\title{
A Design Decision Support System Model for the Wet Space Renovation of Elderly People's Residences
}

\author{
Yaprak Sagdic ${ }^{\dagger}$ and Halime Demirkan*
}

This paper discusses the problems that need to be considered when elderly people renovate their bouses, and particularly the wet spaces, because they do not fulfil the needs and the requirements of the elderly for aging in place. Therefore field research was conducted in order to identify the variables that are influencing the renovation decisions of Turkish elderly people. Based upon the findings, a comparison of the results of the empirical study with the proposed solutions of design guide books is made. The collected data are used to develop Design Decision Support System (DDSS) model for the wet space renovation of the residences used by Turkish Elderly.

\section{Introduction}

Architectural design guides do not always present adequate solutions for the needs of human beings changing with time. The aging process causes many changes in human nature, resulting in environmental interactions. From an architectural point of view, the environment remains the same until human interference causes it to change. From a human point of view, the person using the environment prefers to stay in this same environment with some improvements made to the units, which does not serve well, with respect to the changing needs [1].

In many design guides $[2,3,4,5,6,7]$, the necessary renovations for people with changing needs are stated with a special emphasis given to the needs of people who have extreme mobility impairment like wheelchair users. The needs of the aging people are mentioned in a general context or with a few sentences, and many of the recommendations are not specifically useful for all of the people who have minor limitations. As a result, it becomes hard to find useful information for a specific client, and it takes too much time.

While determining the influential factors on the decisions of the Turkish elderly people related to house renovations, it has been found that two different factors were stated in the previous studies $[8,9]$ as income level and psychological profile of eldely people. The first study was belonging to Imamoglu and Imamogiu [8] who accepted retirement as a better

\footnotetext{
- Bilkent University, Faculty of Art, Design and Architecture, Department of Interior Architecture and Environmental Design, 06 533, Ankara, Turkey. Corresponding author.
}

index than ageing in their sampling procedure. They found that the income level is more important in housing problems than ageing because the income of a working person decreases to a ratio of $2 / 3$, when he/she retires. However, Turel [9] mentioned that as a person gets older, his psychological profile is also changing and, therefore, some elderly people prefer not to change even a tap although they have enough economic power.

Compared to the construction of a building from the initial phase, the renovation of a design is not an easy procedure, because the changing needs of human beings due to age require knowledge from many different sources. Knowledge-based systems still promise to be powerful tools in solving architectural design problems. If low-level design decisions can be made by the computer, within a given time slice, there should be an improvement in the quality of design in an interactive environment since more time can now be allocated for more complex decisions [10].

In this study, a solution is proposed through a Knowledge-Based System (KBS) model which assists the human designer during the design process of the wet spaces of the residences for the elderly. Here, the authors accept Mitta and Ellis's [11] definition of KBS as "providers of recommendations, guidelines, or problem solutions inferred from values assigned to input conditions (236)." There are a variety of possible ways of encoding knowledge, Design Decision Support System (DDSS) model is a prototype of a knowledge-based system that can serve a designer during the design process especially in data collection and design criticism phases.

It is obvious that a DDSS still has many limitations, and it can not replace personal judgements on the change of values with time, but at least it can 
help the user on aspects which are not well known to user. Among the many DDSS models mentioned by Timmerman [12], the one proposed in this study aims to help a designer who wants to make renovations in a pre-built wet space to allow for changes influencing the capability of an older person. Consequently, the model is introduced during the initial state of the design procedure, and is implemented through knowledge acquisition process.

\section{The Model}

\section{Design Procedure}

In its most general formulation, a design procedure starts with needs and desires, continues with a design process, and ends with a design solution [13]. In this approach, a statement of needs and desires is what usually motivates or initiates a design problem. Initially the designer should obtain information on what is to be designed and the constraints and requirements of the designed anefact. The designer should then use a broad spectrum of knowledge, which includes codes, rules and habits pertaining to the behaviour of people, artefacts and spaces. The solution is a design description created during the design process.

It is obvious that the needs and desires of a person are influenced by personal characteristics, including the physical, intellectual and psychological aspects, and environmental characteristics, including the nature and the built environment [14], as depicted in Figure 1, which is developed from the schema of Bernaras by the authors [13].

A design solution of the type shown in Figure 1 effects the environmental characteristics, since it becomes a part of the environment in spatial design, and this phenomenon continues in a loop. Like the environmental characteristics, the personal characteristics are also influenced by the design solution and by time. The effect of time on the physical, intellectual and psychological characteristics is very dynamic, especially during two periods of human life: namely, childhood and old age.

\section{Knowledge Acquisition}

Knowledge acquisition is an active modeling process. A designer constructs a conceptual model of the artefact by abstracting knowledge from mind. He determines his own priorities on the acquired knowledge and recalls his analogies, memories and forms the presolution model. These conceprual representations are being linked both with extemal forms of knowledge and with the intemal representations of the model [15].

According to Shaw and Woodward [16], the process of knowledge base development begins with the initial selection of the problem, application or domain definition, moves through iteration of knowledge acquisition activity, knowledge base development, and verification, and end with delivery and a plan for maintaining the KBS in its application environment.

Knowledge acquisition techniques [16] focus on the direct elicitation of knowledge from a human source in a manner that allows relacively easy representation of this knowledge in a computer environment. Rappaport and Gaines [17] define three major knowledge sources: "knowledge encoded in relevant media, such as books, journals, and videotapes; knowledge available by observing and modeling the relevant domain; and knowledge available from discourse with, and observation of, the relevant community (51-52)."

After the knowledge acquisition process, one of the most important 'bottle-necks' [18] of developing a KBS [16,19], is a domain that is specified by the system in which everything can be solved and guided.

\section{The Knowledge Base of DDSS Model}

The knowledge environment shown in Figure 2 is an expansion of the knowledge acquisition process explained by Rappaport and Gaines [17] and developed by the authors. The relevant media are the design guides and books about gerontology and ergonomics, written by the experts in the field of aging and architectural design who are the relevant part of the relevant community. By using the information coming from the relevant media and community, a questionnaire was prepared to define the relevant domain of this study.

Variables related to the personal characteristics are age, sex, stature (physical height), and disability (either by birth or later illness)-mental disability, physical disability and related assisting devices. Cultural variables are birth place, education level. Economic variables are the personal

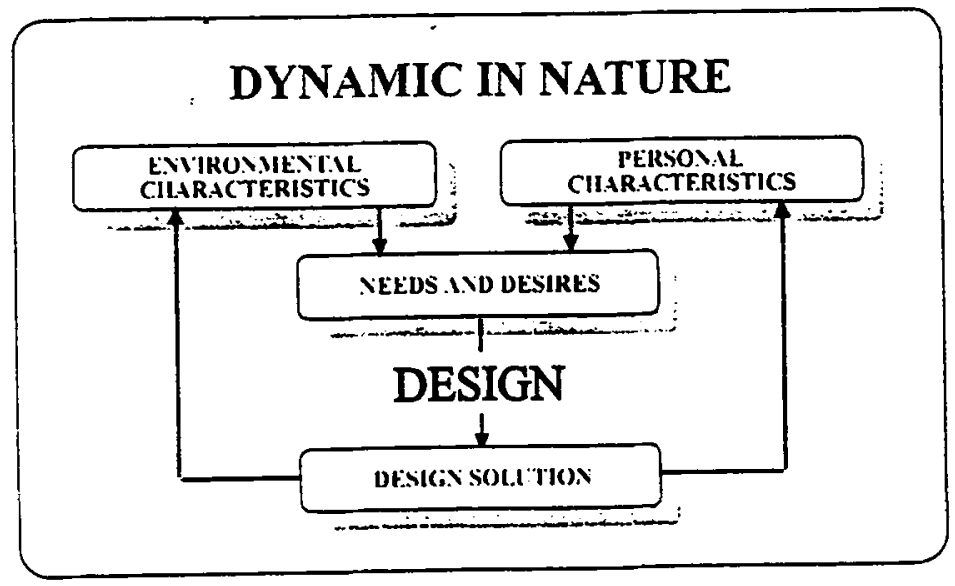

Figure 1. Components influencing the needs and desires.

previous experiences and information stored in the memory. This abstraction is aided by the use of interpretation. As an example, in designing a kitchen for the elderly, the designer has images of such spaces in his income and family size. The variables related to the environmental characteristics, on the other hand, are stated as years spent in a house, the house ownership, number of people living in the house and existing 


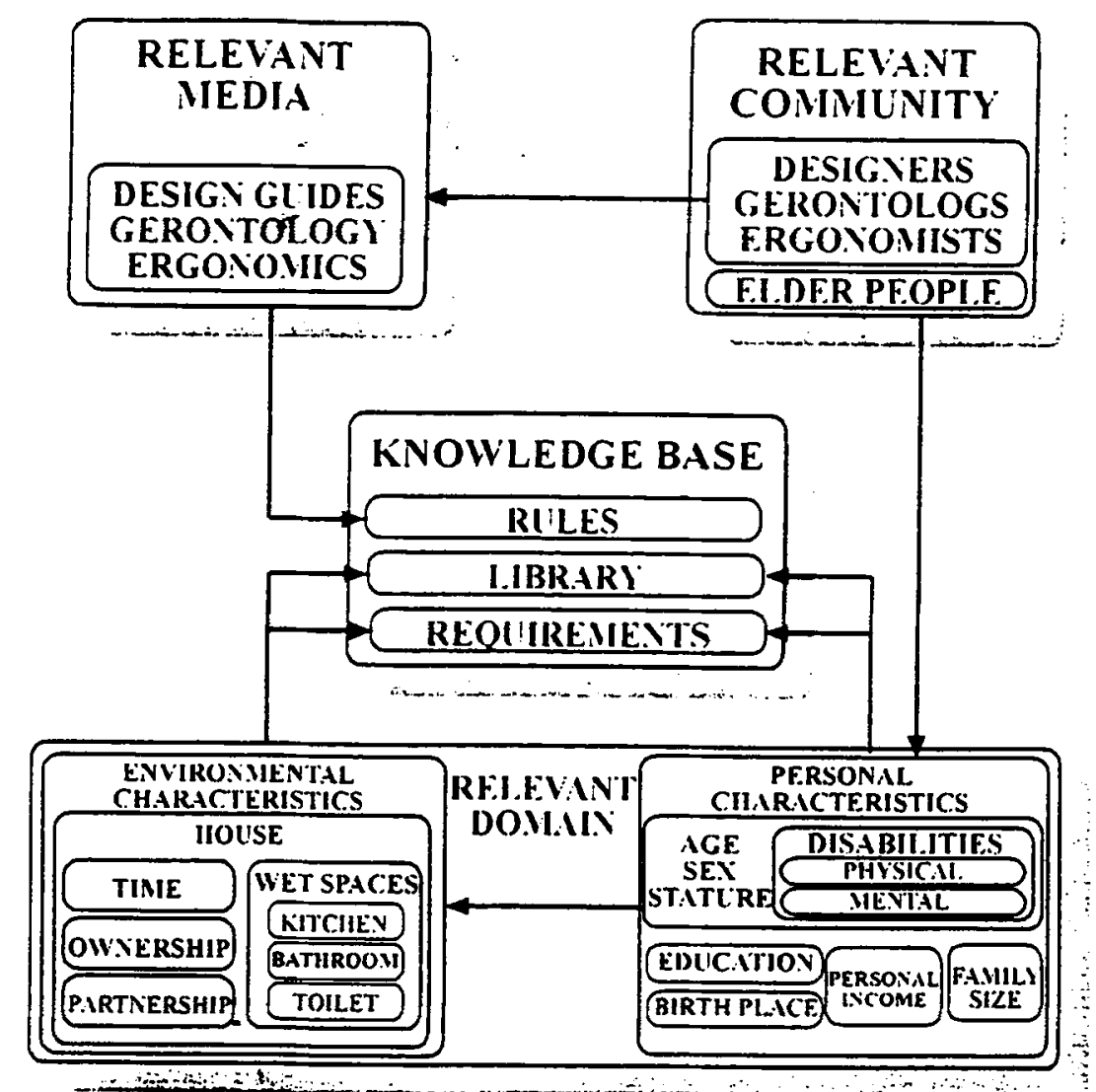

Figure 2. The relations among the relevant media, relevant community and relevant domain in knowledge acquisition in DDSS.

situation of the wet spaces - kitchens, bathrooms and toilets.

\section{Domain Specification and Criticism Process}

All theacquired information is used in the domain specification process. This defines the requirements related to the domain, the library of the objects related to the domain and the rules which define the relations between the objects as shown in Figure 3.

The system interacts through a set of choices. The designer, who uses the system, can define the part of the residence that could be designed for aspecific type of client. The specification of domain is drawn up after a few stages. The specified domain communicates with a library which contains a set of fumiture objects (Figure 2). These objects are the conceptual images of the furniture and other interior elements that are determined by the relevant media. The objects related to the same unit and the units of the same wet space are clustered according to their qualitative and quantitative properties, and physical and conceptual relations (Figure 4).

Each object in each unit is classified hierarchically according to its importance in the space. A water closet (WC) can be given as an example of hierarchy because it is hierarchically the most important furniture for a toilet space. All the other related furniture like reservoir, toilet paper holder and grab bars, if necessary, have secondary importance compared to WC, since they must be placed according to WC.
After this classification was defined, a map, which spatially clusters entities and attributes within a subdomain and which prompts the expert to add higher-level entities structuring the domain [16], is used while stating the physical and conceptual relationship rules of each object

These objects are used as design tools and they can provide the linguistic standard between the user and the computer. There are two implications to the word 'linguistic'. One is the 'language' which consists of the symbols used for communication. The other is the 'communication' which is the information transformation to reach to the same knowledge source. Here, the designer can make use of the abstraction of objects in order to do his/her conceptual design. Metaphorically, it will be just like gathering the letters of a word and the words of a sentence[16].

The rules related to the quantitative properties determine the physical dimensions, and the number of objects according to the specified domain. In qualitative properties, the required characteristics of an object are specified, e.g., the material suitable for an object. The physical relations among objects determine a suitable place (in the coordinate system) for an object with respect to the other objects in the same unit. The conceptual relations are the functional relations between the group of objects disregarding the real shapes and exact places of each item.

A function-graph, which shows the primary and secondary functions, without cross intersections, depending on the object, is used to define 


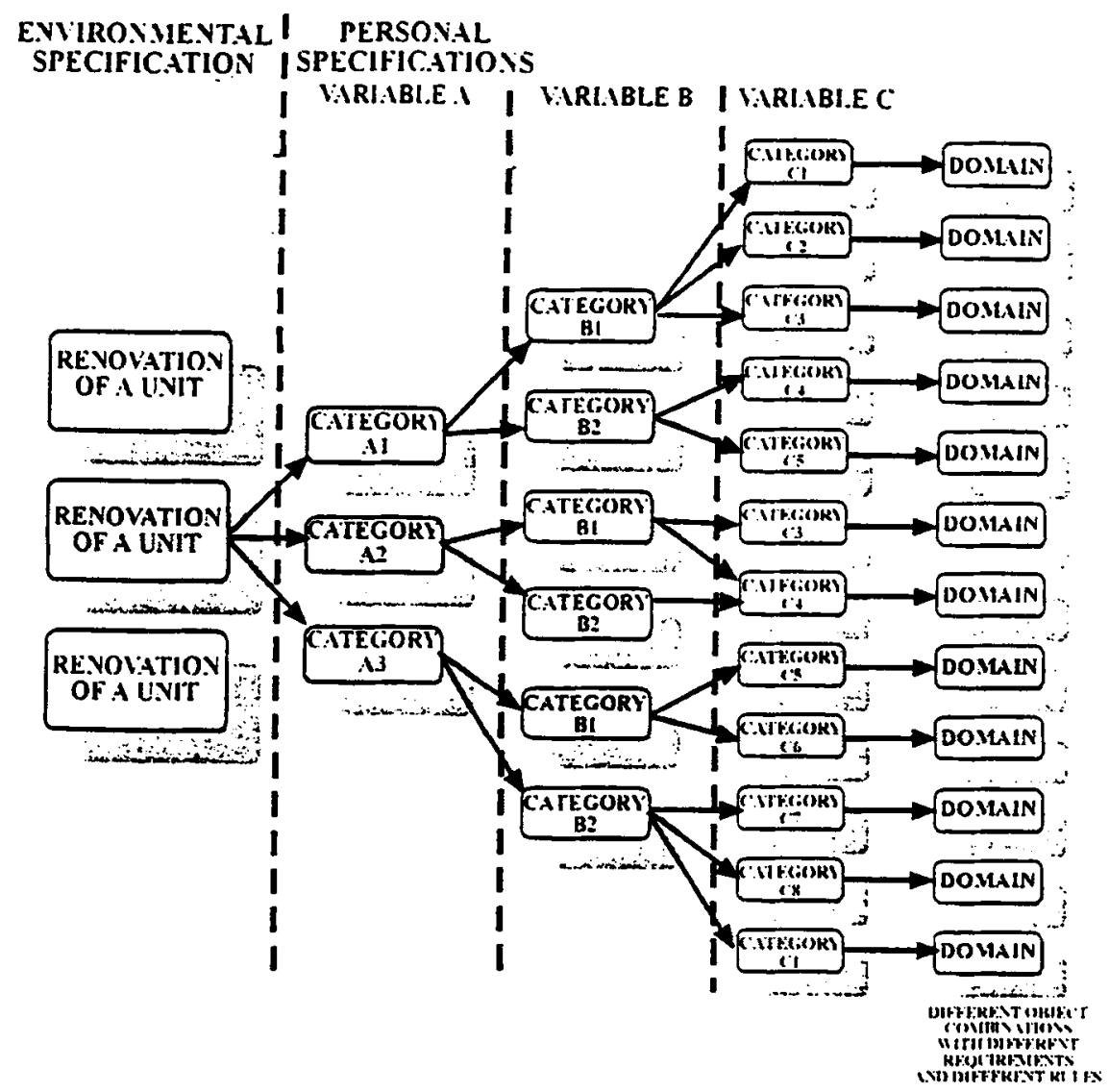

Figure 3. Domain specification process after knowledge acquisition.

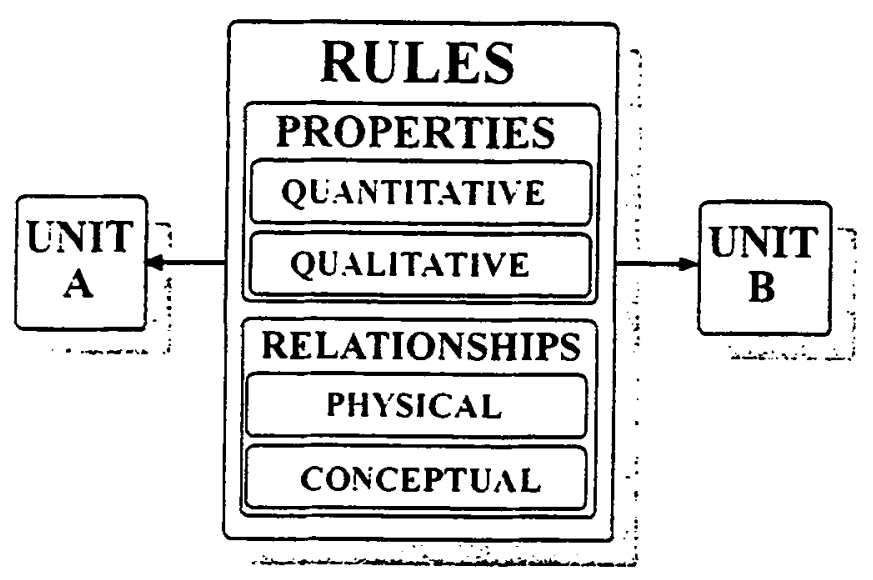

Figure 4. Relations between two objects in the same unit. 
the conceptual design of each unit. These graphs are expected to help the designer to understand the conceptual relationships between two or more objects. These function graphs are used in the criticism part of the model which is an important part of the DDSS.

After the objects, related to the specific domain, space and function, are defined, the designer creates his conceptual design by using these objects (Figure 5). Then, the system criticizes the conceptual model and if there is an unacceptable relation among the objects as in Figure $6(\mathrm{~A})$; the system criticizes the design with respect to the acquired knowledge during the knowledgeacquisition process, and the rules which determine the relationships and properties of each object. DDSS wams the designer on the intersection points, and the designer should correct the places of the objects to reach to an acceptable solution, as in Figure 6 (B).

In spatial clustering the relations of the objects are criticized according to the rules of physical relations. In conceptual relations in a group, the conceprual relations of the objects are criticized with respect to the rules shown in Figure 4. In a hierarchical clustering criticism, the hierarchical importance of the rules is deduced and the priority is determined according to the rules, considering any conflicts. If all the criticisms are positive then a conceptual design solution is found.

\section{Method}

The personal and environmental characteristics (see Figure 1) are determined through the information collected in a field research conducted among 39 Turkish elderly people, who were chosen by stratified random sampling method. These data are used in the knowledge acquisition process of DDSS model. The samples were visited in their houses and interviewed by the authors. Each participant was asked 93 questions and observations were made on the present wet spaces. The questions were related to the personal profile of the participant ( 9 questions), the disability profile of the participant (13 questions) and wet spaces of the house in which the participant was living (3 general questions, 30 questions and observations for kitchen, 38 questions and observations for the bathroom-toilet areas). The mean interview duration was 55 minutes with a standard deviation of 19 minutes.

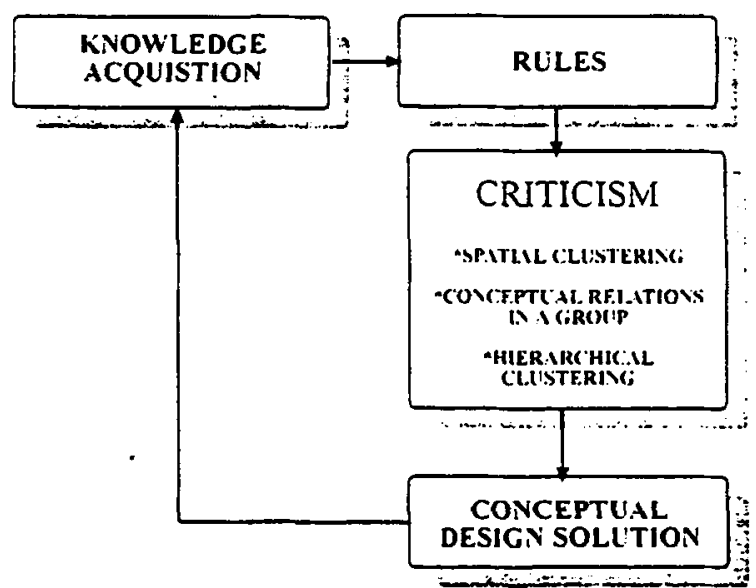

Figure 5. Criticism of the conceptual design model.

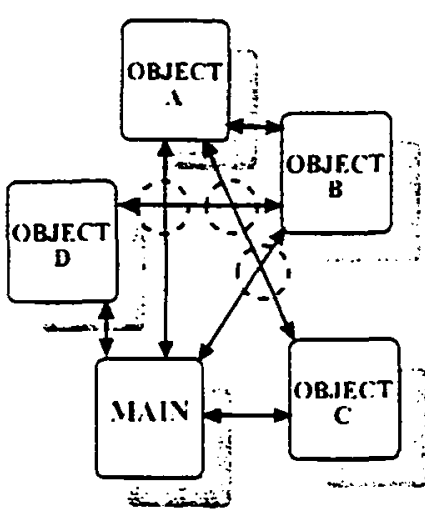

(A)

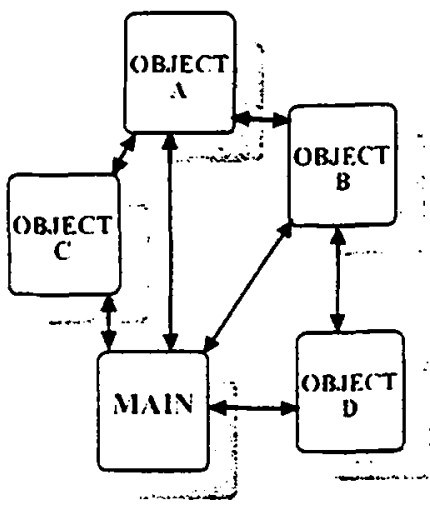

(B)

Figure 6 (A) Unacceptable relations and (B) corrected relations among the objects of related domain. 


\section{Results}

\section{Related to the Personal Profile}

The young-old people (60-74-years old) are $66.7 \%$, the old-old people (75-84-years-old) are 30.8\% and the oldest people ( 85 and more-yearsold) are $2.5 \%$ of the total participants of this study. The ratio of men is very low (15.4\%) whereas the women are nearly five times more than the men $(84.6 \%)$. The mean stature is calculated as $167.16 \mathrm{~cm}$ (standard deviation= 11.75 ) for men, and $154.84 \mathrm{~cm}$ (standard deviation $=28.67$ ) for women.

Among the participants, there is no illeterate person. Only one of the female participants (2.5\%) did nothaveaschool diplomaand $23.1 \%$ of the participants graduated from a primary school, $15.4 \%$ graduated from a secondary school, $38.5 \%$ graduated from a high or a technical school and $20.5 \%$ graduated from a university.

All the male participants had a job and $83.33 \%$ are still working after retirement. Although more than half of the female participants (54.5\%) had a profession to eam their living only $27.7 \%$ of them had actually worked and $5.12 \%$ of them are still working.

$5.0 \%$ of the participants had no income at all or very low income. $28.2 \%$ are in low income level, $33.3 \%$ are in middle income level, $23.1 \%$ are in upper middle income level and $10.4 \%$ are in high income level. The birth-place distribution of the participants is as follows: $7.7 \%$ were borm in a village, $20.5 \%$ were bom in a town and $71.8 \%$ were born in metropolitan areas.

In this study, $87.1 \%$ of the participants have a visual disability. $38.5 \%$ of the participants are suffering from low level of hearing, and among these people only $6.7 \%$ has the impairment due to an illness. According to the self-reports of the participants $20.5 \%$ of them do not have any motor system illness.

A small percentage (12.5\%) of the sample do not use any assisting device. Among the users, the assisting devices as eye-glasses against low vision ( $82.0 \%$ ), audial devices against low hearing $(2.5 \%)$ and cane and walker against motor disabilities (10.2\%) could be stated.

\section{Related to Statistical Analysis}

In the beginning of the field research on the relevant community (elderly people), all of the mentioned variables were supposed to have an influence over the relevant domain. The environmental characteristics related to kitchens, bathrooms and toilets evidenty determine the library of appropriate fumiture and the requirements of the knowiedge acquisition process (see Figure 2). However, after statistical analyses it was found that the decisions about the renovations in one's house is not independent of personal characteristics [using Chi-Square Tests $\left(c^{2}\right)$ ], and there is a significant difference among the groups in terms of these variables (using Two-Way Anatysis of Variance by F-tests). Some of the personal characteristics were found to affect the success of the environmental renovation decisions more than the others. These relations can be seen in detail in Figure 7 and 8 (see Note).

In the kitchen areas (Figure 7), the doorway unit renovation decision, which deals with the entrance door to the kitchen and the threshold objects, is influenced by the type of assisting device, which is used by the elderty person ( $F_{4,4}=12.66, \alpha=0.025$ ). The floor unit renovation decision, showing the floor finish material, is the unit which is influenced by the greatest number of variables, including the user's $\operatorname{sex}\left(F_{1,1}=32.11\right.$, $\alpha=0.005$ ), birth place (as being bom in a big city or in a town or in small village) $\left(F_{22}=56.97, \alpha=0.025\right)$, education level $\left(F_{44}=5.8, \alpha=0.1\right)$, and type of motor disabilities type $\left(F_{3,5}=21.73, \alpha=0.005\right)$. The cook-top unit renovation decision, which is composed of stove, oven, hood and a mirror on the back wall, is only affected by the assisting devices, used by the elderly people. In other words, assisting device usage is not independent of cook-top renovations in residential kitchens $\left(\alpha_{4}^{2}=14.995, \alpha=0.005\right)$.

It is worth mentioning that the cabinet unit's renovation decision, consisting of all the storage units in the kitchen, is not influenced by any of the variables, although they were mentioned as the parts of the kitchens most frequently renovated $[14,20,21]$. The sink unit renovation decision, which is composed of sink, tap, and drain, is influenced by the sex of the people $\left(F_{1,1}=17.64, \alpha=0.005\right)$ and by the type of the physical disability $\left(F_{5,5}=4,37, \alpha=0.1\right)$. The success of the spatial arrangement units' renovation decision, including removal of a balcony door for

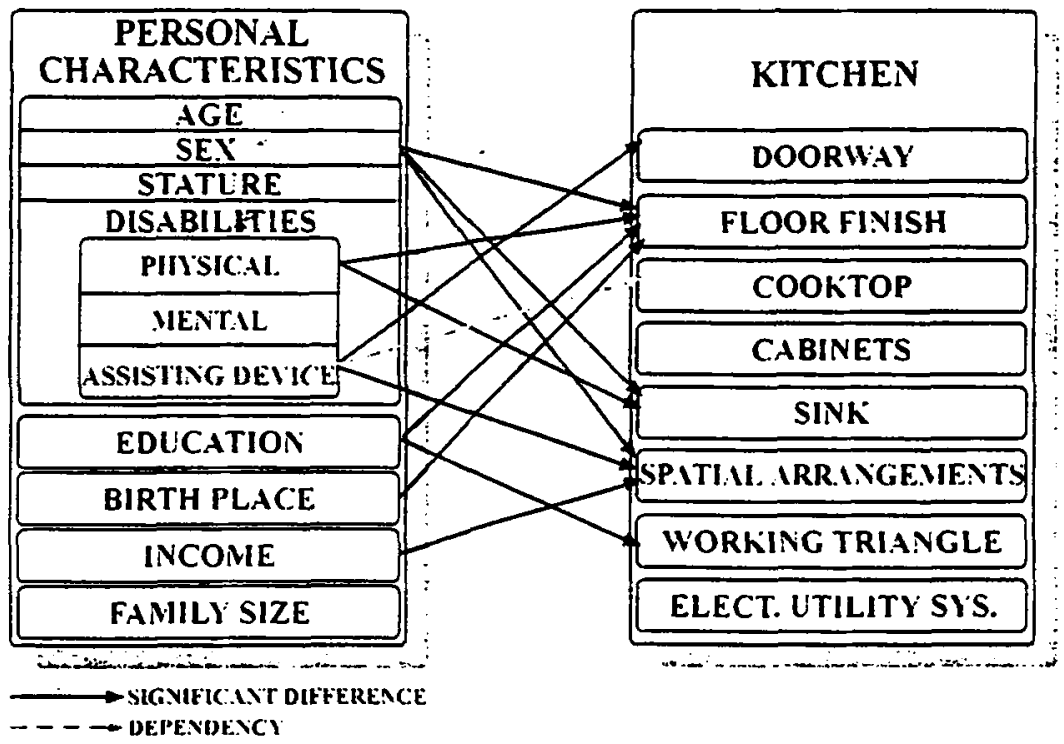

Figure 7. The influence of personal characteristics over the success of the kitchen unit's renovation decisions. 


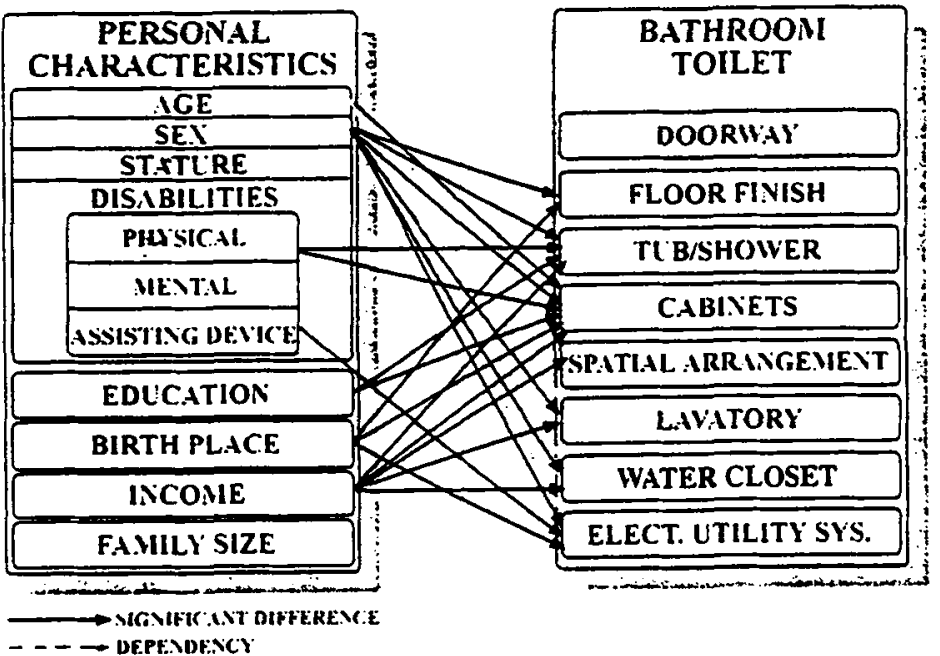

Figure 8. The influence of personal characteristics over the success of the batbroom-toilet unit's renovation decisions.

enlarging the space, connecting the kitchen to another room or moving one of the walls towards the inside or outside of the kitchen area, shows significant difference, if it is done by different sexes $\left(F_{1,1}=4.57, \alpha=\right.$ 0.001 ), different personal income groups $\left(F_{5 s}=6.21, \alpha=0.05\right.$ ) and different people using different assisting devices $\left(F_{4,4}=12.42, \alpha=0.025\right)$. The work triangle, which is very important for the efficiency of a kitchen, is only affected by the education level $(F,=5.8, \alpha=0.1)$. Finally, the electrical utility system, including the light sources, the switches and outlets, is not affected by any kind of personal characteristics.

Figure 8 shows the influence of the personal characteristics on the bathroom-toilet units. Although design guides [2,3] generally mention the importance of bathroom doors opening towards the outside of the bathroom area, none of the variables influenced the doorway renovation decisions. Bathroom-toilet floor finish renovation decision is influenced by the sex of different persons $\left(F_{1,1}=9, \alpha=0.01\right)$, and birth places $\left(F_{22}=\right.$ $56.97, \alpha=0.025)$. The tub/shower unit renovation, which is composed of the tub or shower area, the faucet, the seating units and the grab bars, are influenced by the user's sex $\left(F_{1,1}=21.16, \alpha=0.005\right)$, education level $\left(F_{44}=6.11, \alpha=0.01\right)$, personal income $\left(F_{55}=4.16, \alpha=0.01\right)$ and motor disability type $\left(F_{5,5}=28.27, \alpha=0.005\right)$. The bathroom cabinets' renovation decision, consisting of every type of storage unit in the bathroom area, is influenced by the greatest number of variables. People from different age groups $\left(\chi_{2}^{2}=4.73, \alpha=0.1\right)$, sexes $\left(F_{1,1}=81, \alpha=0.005\right)$, birth places $\left(F_{2,2}=236.26, \alpha=0.005\right)$, education levels $\left(F_{4,4}=6.40, \alpha=0.05\right)$, personal income levels $(F,=8.71, \alpha=0.025)$ and type of motor disabilities $\left(F_{5.5}=11.88, \alpha=0.001\right)$ have different effects on the renovation decisions of the bathroom cabinets. The spatial arrangement of the bathroom-toilet areas, which includes the change of sanitary units and/ or removal of a wall for enlarging the space, are influenced by personal income levels ( $F_{5.5}=6.21, \alpha=0.05$ ). The lavatory unit renovation, which includes the lavatory, water pipes, faucet, faucet control, mirror, medical cabinet, towel bar and an oudlet, is influenced by people having different $\operatorname{sexes}\left(\mathrm{F}_{1,1}=6.76, \alpha=0.01\right)$, and income groups $\left(\mathrm{F}_{5.5}=7.21, \alpha=0.025\right)$. The lavatory unit renovation is not independent of agegroups $\chi_{2}^{2}=6.842$, $\alpha=0.05$ ). The water closet unit, including water closet, reservoir, grab bars and toilet paper holder, is under the influence of same variables as lavatory unit; $\operatorname{sex}\left(F_{1.1}=40.11, \alpha=0.005\right)$, and income $\left(F_{5.5}=4.58\right.$, $\alpha=0.1)$. The water closet unit renovation is not independent of age groups $\left(\alpha_{2}^{2}=5.39, \alpha=0.1\right)$. The final item of the bathroom-toilet spaces is electrical utility system which is distinct from the kitchen's electrical utility system. The design guides [2,3], mention the importance of emergency call buttons in bathrooms. Therefore, the electrical utility system unit of the bathroom-toilet areas includes the emergency call buttons, and this system is under the influence $\operatorname{sex}\left(F_{1,1}=6.25, \alpha=0.01\right)$, birth place $\left(F{ }_{22}=15.83, \alpha=0.1\right)$ and assisting device use $\left(F_{4,4}=5.66\right.$, $a=0.1$ ). The electrical urility system renovation is not independent of age groups $\left(\alpha_{2}^{2}=4.73, \alpha=0.1\right)$,

\section{Conclusion}

In this research, making renovations were statistically found to be not independent of age. Although income is an influential factor in making renovations as supported by Imamoglu and Imamoglu [8], people in the middle and upper middle income level are changing more items than people with high income levels. The reason behind the stated results can be found in the cultural background, depending on the birth place which defines many habitual activities in personal and daily living. The economic independence of the elderly people is also an important issue in decision making, and in the finalization of the renovations.

The sex variable among the personal characteristics is one of the unexpected domain specifiers of the knowledge acquisition process in the system model. Generally, design guide books are stating the necessary changes in wet spaces without referring to the sex of the users. In this study, the female users' approach in three of the eight kitchen unit renovations (floor finish, cook-top and spatial arrangement) are different from that of the male users. Furthermore, in six of the eight bathroom units' renovations (floor finish, tub/shower area, cabinets, lavatory area, WC and electrical utility), there are significant differences between the two sexes. This is an important issue to take into consideration when the kitchens were under the control of women until the last decade, but bathroom and toilet usage were common to both sexes. However, their preferences are significantly different in bathroom-toilet areas than in kitchen areas.

An approach to solve this dilemma for Turkish elderly people can belike 
this. The generation is composed of females who leamed to serve the men, the males who learned to be served by women. Under the influence of this cultural background, the kitchens were thought of as the castles for women who decide on everything in the kitchen. The analysis showed that men are deciding on kitchen renovations as much as the women [22] due to the men's economic power and control of family budget.

Note: Further information about the model and statistical analyses can be obtained from the corresponding author.

\section{References}

1. O. Demirbilek and H. Demirkan: Involving the elderly in the design process. Arcbitectural Science Review. 41: 4, 1998, pp. 157-163.

2. A. Peloquin: Barrier-free Residential Design. New York: McGraw Hill. 1994.

3. L. Harber, R. Mace and P. Orleans: UFAS Retrofit Guide: Accessibility modifications for existing buildings. New York: Van Nostrand Reinhold. 1993.

4. R I. Mace: The Accessible Housing Design File. New York: Van Nostrand Reinhold. 1991.

5. J. DeChiari and J. Callender: Time Saver Standards for Building Types. New York: McGraw Hill. 1990.

6. B. B. Raschko: Housing Interiors for the Disabled and Elderly. New York: Van Nostrand Reinhold. 1982.

7. S. Goldsmith: Designing for the Disabled. London: RIBA Publications. 1976.

8. E. O. Imamoglu and V. Imamoglu: Housing and living environments of the Turkish elderly. Joumal of Environmental Psychology, 12, 1995 , pp. 35-43.

9. G. Türel: Proposals for the solutions of housing for elderly. Housing Question of the Otbers. Ankara, Turkey: Chamber of Architects, 1995, pp. 398-406.

10. H. Demirkan, M. Pultar and B. Özgüc: A knowledge-based space planning system. Architectural Science Review, 35, 1, 1992, pp. 3-7.
11. D. A. Mitta and N. C. Ellis: Development of intelligence design associates: a casestudy.Applied Ergonomics, 24,4,1993, pp. 235-243.

12. H. Timmermans: Design and Decision Support Systems in Architecture. Dodrecht: Kluwer Academic Publishers, 1993.

13. A. Bernaras: Problem-oriented and task-oriented models of design in the common KADS framework. Artificial Intelligence in Design ' 94 . 1994, pp. 499-516.

14. Y.Sagdic:AFramework for a Design Decision Support System Model for the Wet Space Renovation of the Residences Used by Turkisb Elderly People. Ph.D. Thesis. Ankara, Turkey: Bilkent University, 1997.

15. H. Demirkan: Integration of reasoning systems in architecturai modelling activities. Automation in Construction. 7, 1-2, 1998, pp. 229 . 236.

16. M. L. G. Shaw and J. B. Woodward: Modelling expert knowledge. Knowledge Acquisition. 2, 1990, pp. 179-206.

17. A. T. Rappaport and B. R. Gaines: Integrated knowledge-base building environments. Knowledge Acquisition.2, 1990, pp. 51-71.

18. J. A. Rantanen: Hypermedia in knowledge acquisition and specification of yuser interface for KBS: An approach and a case study. Knowledge Acquisition. 2, 1990, pp. 259-278.

19. W. Karbach, M. Linster and A. Voss: Models, methods, roles and tasks: many labels-one idea? Knowledge Acquisition. 2, 1990, pp. $279-299$.

20. H.Demirkanand S. Kutlusoy: Housing conditions and activities of the middle-income Turkish household. International Journal of Housing Science and Its Applications, 22,2,1998, pp. 125-136.

21. Y. Sagdic: The influence and requirements of respect to elderly people in interior architecture as a cultural value. Culture and Space: Building and Life Congress '95. Bursa: Turkey: Chamber of Architects Bursa Section., 1995, pp. 291-299.

22. Y. Sagdic and H. Demirkan: Different aspects of being elderty in residential wet spaces. IEA,97-13 Tiennial Congress of the Intemational Engonomics Ascociation. Tampere, Finland: Finnish Institute of Occupational Health, 5, 1997, pp.609-611. 